\title{
Overview of the Altair Lunar Lander Thermal Control System Design and the Impacts of Global Access
}

\author{
Ryan A. Stephan ${ }^{1}$ \\ NASA Johnson Space Center, Houston, Texas, 77058
}

\begin{abstract}
NASA's Constellation Program (CxP) was developed to successfully return humans to the Lunar surface prior to 2020. The CxP included several different project offices including Altair, which was planned to be the next generation Lunar Lander. The Altair missions were architected to be quite different than the Lunar missions accomplished during the Apollo era. These differences resulted in a significantly dissimilar Thermal Control System (TCS) design. The current paper will summarize the Altair mission architecture and the various operational phases associated with the planned mission. In addition, the derived thermal requirements and the TCS designed to meet these unique and challenging thermal requirements will be presented. During the past year, the design team has focused on developing a vehicle architecture capable of accessing the entire Lunar surface. Due to the widely varying Lunar thermal environment, this global access requirement resulted in major changes to the thermal control system architecture. These changes, and the rationale behind the changes, will be detailed throughout the current paper.
\end{abstract}

\footnotetext{
${ }^{1}$ Thermal Systems Engineer, Crew and Thermal Systems Division, Mail Code EC-2
} 